\title{
Oxidative damage and photosynthetic impairment in tropical rice cultivars upon exposure to excess iron
}

\author{
Samuel de Souza Pinto ${ }^{1}$, Anna Elisa de Souza ${ }^{1}$, Marco Antonio Oliva ${ }^{2}$, Eduardo Gusmão Pereira ${ }^{1 *}$
}

IFederal University of Vicosa - Campus Florestal, Rod. LMG 818, km 06 - 35690-000 - Florestal, MG - Brazil. 2University of Vila Velha, Av. Comissário José Dantas de Melo, 21 - 29102-920 - Vila Velha, ES - Brazil.

*Corresponding author <egpereira@ufv.br>

Edited by: Daniel Scherer de Moura

Received March 20, 2015

Accepted August 17, 2015

\begin{abstract}
Iron plays a pivotal role in the redox reactions of photosynthesis and metabolic processes such as chlorophyll synthesis. Iron availability in waterlogged soils can reach toxic levels and promote oxidative stress. Fe toxicity is the most concerning of stresses for rice in many lowland environments around the world and may cause severe impairments in rice photosynthesis. This study aimed to investigate the extension of oxidative stress after excess Fe exposure and its effects on the photosynthesis of rice cultivars with differential sensitivity. Three Brazilian rice cultivars (EPAGRI 107, BRSMG SELETA and BR IRGA 409) were grown in Hoagland nutrient solution ( $\mathrm{pH} 4.0$ ) with two Fe-EDTA doses corresponding to excess Fe $(7 \mathrm{mM})$ and control (0.009 $\mathrm{mM}$ ) treatments. After just three days of excess Fe exposure, there was a significant increase in iron concentration in the shoots. The BR IRGA 409 cultivar exhibited higher Fe accumulation in its shoots, and the EPAGRI 107 cultivar recorded the lowest values, which were below the critical toxicity level, as a resistance strategy. Impairment in light energy partitioning and oxidative damage became evident before changes in stomatal resistance, chlorophyll content, maximal PSIl quantum yield or visual symptoms for the most sensitive cultivar (BR IRGA 409). The photosynthesis limitations, in addition to the impairment of excess energy dissipation in rice from iron toxicity, are the results of oxidative damage.

Keywords: TBARS, iron toxicity, light energy dissipation, oxidative stress, photosynthesis
\end{abstract}

\section{Introduction}

Iron $(\mathrm{Fe})$ is a micronutrient that plays important physiological roles in plants as a component of enzyme cofactors that catalyze redox reactions in fundamental metabolic processes. In oxygenic photosynthesis, Fe is a cofactor in both photosystems (PSII and PSI) and in the cytochrome (Cyt) $b_{6} / f$ complex. Moreover, it is required for chlorophyll biosynthesis and to promote the structural integrity of photosynthetic reaction centers and light-harvesting complex (LHC) subunits (Guerinot and Yi, 1994; Msilini et al., 2011; Yadavalli et al., 2012). However, the same redox properties that make Fe suitable to the electron transfer chain in photosynthesis is also responsible for its toxic effects when it is present in excess because of reactive oxygen species (ROS) overproduction (Kobayashi and Nishizawa, 2012).

In addition to its abundance in the earth's crust, iron in aerobic soils is found mostly in the form of insoluble $\mathrm{Fe}^{3+}$ oxides or hydroxides, which decrease Fe bioavailability to plants (Stein et al., 2014). However, iron toxicity may occur in waterlogged soils as a consequence of the high amounts of reducible $\mathrm{Fe}$, low $\mathrm{pH}$, and low cation-exchange capacity (Becker and Asch, 2005). In fact, Fe toxicity is the most widespread nutritional disorder that affects wetland rice production (Dobermann and Fairhurst, 2000).

Fe toxicity symptoms in rice are frequently linked to a "bronzing" appearance in leaves, that is brown spots starting from the leaf tip that develop into purple, reddish-brown spreading towards the leaf base. The roots become dark brown in color and develop poorly, and exhibit a scanty and coarse aspect (Becker and Asch, 2005;
Silveira et al., 2009). Iron toxicity also reduces growth and yield (Dorlodot et al., 2005), causes nutritional disorders (Pereira et al., 2014) and severe impairment in rice photosynthesis (Pereira et al., 2013).

Rice photosynthesis is sensitive to Fe excess through an initial increase in stomatal resistance, lowering the $\mathrm{CO}_{2}$ mesophyll concentration and through non-stomatal limitation due to biochemical and photochemical impairment after severe stress (Pereira et al., 2013). We propose that light energy partitioning impairment and oxidative damage, which is more severe in cultivars with high sensitivity, may take place before the non-stomatal limitation because of the Fe overload in the roots. This study aimed to investigate the oxidative damage triggered by Fe toxicity and its effects on the photosynthetic variables in rice cultivars with differential sensitivity.

\section{Materials and Methods}

\section{Plant materials and experimental conditions}

The seeds of three rice (Oryza sativa L.) cultivars (EPAGRI 107, BRSMG SELETA and BR IRGA 409) were surface sterilized with $10 \%$ sodium hypochlorite for 10 min and then thoroughly washed in deionized water. The seeds were germinated on moistened paper for a $12-\mathrm{h}$ photoperiod (200-250 $\left.\mathrm{mmol} \mathrm{m}^{-2} \mathrm{~s}^{-1}\right)$, at a temperature of $28{ }^{\circ} \mathrm{C}$ and a relative humidity of $100 \%$ for $72 \mathrm{~h}$ in a germination chamber. The seedlings were then transferred to greenhouse conditions and grown hydroponically in non-aerated Hoagland nutrition solution at half-strength (Hoagland and Arnon, 1938) with macronutrients (mM) in the following composition: $\mathrm{NO}_{3}(7) ; \mathrm{NH}_{4}(0.5) ; \mathrm{K}(3)$; 
Ca (2); $\mathrm{Mg}(1) ; \mathrm{P}(0.5) ; \mathrm{S}(1)$; and micronutrients $(\mu \mathrm{M})$ : $\mathrm{Fe}$ (9); B (23); Mn (4.5); Zn (0.4); Cu (0.15); Mo (0.05). The nutrient solution was renewed weekly and the $\mathrm{pH}$ adjusted to 4.0 daily. $\mathrm{Fe}^{2+}$ treatments were applied when the seedlings reached V6 growth stage (Counce et al., 2000). Fe was supplied in the form of Fe-EDTA (equimolar $\mathrm{FeSO}_{4} \cdot 7 \mathrm{H}_{2} \mathrm{O}$ plus EDTA) at concentrations of 0.009 (control) and $7 \mathrm{mM}$.

The lowland rice cultivars were obtained from distinct breeding institutions in Brazil. The BR IRGA 409 cultivar is widely cultivated in the state of Rio Grande do Sul since its release to farmers in 1979, being previously characterized as susceptible to Fe toxicity (Stein et al., 2014). The EPAGRI 107 cultivar was released in 1994 in the state of Santa Catarina. This cultivar is considered resistant to Fe toxicity but is not highly cultivated nowadays. The BRSMG SELETA cultivar is considered suitable for cultivation in the state of Minas Gerais (Soares et al., 2005).

\section{Morphological variables and iron concentration in tissues}

Changes in growth and shoot iron concentrations were measured after 3, 5, 7 and 9 days of excess Fe exposure. The length and dry weight of shoots and roots were measured. The plant material was dried at $75{ }^{\circ} \mathrm{C}$ until it reached constant weight, and then the root and shoot dry weights were determined.

The iron concentration in the shoots was determined by atomic absorption spectrophotometry after wet-digestion with a nitric-perchloric acid solution (3:1) at $200{ }^{\circ} \mathrm{C}$ (Tedesco et al., 1997).

\section{Chlorophyll index}

Leaf relative greenness was measured with the non-destructive chlorophyll meter ClorofiLOG. Four readings were averaged to represent the mean chlorophyll index value of each replicate. All non-invasive sampling was performed on a part of the leaf that was equivalent to one-third the length of the entire leaf from the tip. The index for total chlorophyll, chlorophyll $a$ and chlorophyll $b$ and the chlorophyll $a / b$ ratio were evaluated at 3, 5, 7 and 9 days after the plant was exposed to excess Fe.

\section{Gas exchange measurements}

Gas exchange measurements were taken from attached fully expanded leaves by using a portable photosynthesis system (LCA-4) to determine the net $\mathrm{CO}_{2}$ assimilation rate $\left(A, \mu \mathrm{mol} \mathrm{m} \mathrm{m}^{-2} \mathrm{~s}^{-1}\right)$, stomatal conductance $\left(g_{\mathrm{s}^{\prime}} \mathrm{mol} \mathrm{m}^{-2} \mathrm{~s}^{-1}\right)$ and transpiration rate $\left(E, \mathrm{mmol} \mathrm{m}^{-2} \mathrm{~s}^{-1}\right)$. The measurements were taken in a narrow-leaf chamber $\left(11.35 \mathrm{~cm}^{2}\right)$ by using an integrated light source with saturating irradiance $\left(1000 \mu \mathrm{mol}\right.$ photon $\left.\mathrm{m}^{-2} \mathrm{~s}^{-1}\right)$ (Pereira et al., 2013) at a temperature from 26 to $30^{\circ} \mathrm{C}$ and an atmospheric $\mathrm{CO}_{2}$ concentration ranging from 380 to 410

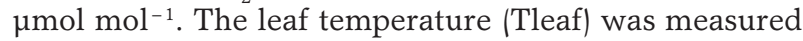
with a thermocouple that was placed inside the cuvette. The leaves were placed in the cuvette to stabilize for at least two minutes before the first recording. Three recordings were then made at approximately 1-min intervals to ensure the stability of the readings. The ratio of the intercellular to ambient $\mathrm{CO}_{2}$ concentrations $(\mathrm{Ci} /$ Ca) was also calculated.

\section{Chlorophyll fluorescence measurements}

To test the hypothesis that sensitivity to Fe toxicity is linked to impaired light energy utilization, the BR IRGA 409 cultivar (the most sensitive) was used for leaf chlorophyll fluorescence image analysis at 1,3,5 and 7 days after excess $\mathrm{Fe}$ exposure in another series of experiments. Pixel value images of the fluorescence variables were displayed with the help of a color code ranging from black (0.000) to pink (1.000). After dark adaptation (30 $\mathrm{min})$, the minimal fluorescence $\left(\mathrm{F}_{0}\right)$ was measured under a weak modulating light $\left(0.5 \mu \mathrm{mol} \mathrm{m} \mathrm{m}^{-2} \mathrm{~s}^{-1}\right)$, and maximal fluorescence $\left(\mathrm{F}_{\mathrm{m}}\right)$ was induced by a saturating pulse of light $\left(2400 \mu \mathrm{mol} \mathrm{m} \mathrm{m}^{-2} \mathrm{~s}^{-1}\right)$. The maximal PSII quantum yield was determined as $\mathrm{F}_{\mathrm{v}} / \mathrm{F}_{\mathrm{m}}$ (Kitajima and Butler, 1975) where $\mathrm{F}_{\mathrm{v}}$ is the difference between $\mathrm{F}_{\mathrm{m}}$ and $\mathrm{F}_{0}$. After measuring $\mathrm{F}_{0}$ and $\mathrm{F}_{\mathrm{m}^{\prime}}$ the leaf was exposed to increasing light intensities varying from 5 to $965 \mu \mathrm{mol}$ $\mathrm{m}^{-2} \mathrm{~s}^{-1}$ in nine steps lasting $40 \mathrm{~s}$ each. At the end of each light intensity, a saturation pulse was applied to produce $\mathrm{F}_{\mathrm{s}}$ and $\mathrm{F}_{\mathrm{m}}$ ' measurements from which automatic images of the fluorescence variables were generated by ImagingWin software. The minimal fluorescence in a light-acclimated state $\left(\mathrm{F}_{0}{ }^{\prime}\right)$ was calculated by using the Oxborough and Baker (1997) approximation as follows: $\mathrm{F}_{0}{ }^{\prime}=\mathrm{F}_{0} /\left(\mathrm{F}_{\mathrm{m}}-\mathrm{F}_{0} / \mathrm{F}_{\mathrm{m}}+\mathrm{F}_{0} / \mathrm{F}_{\mathrm{m}}{ }^{\prime}\right)$. The non-photochemical quenching of fluorescence (NPQ) was used to estimate the rate constant for thermal energy dissipation as NPQ $=\left(\mathrm{F}_{\mathrm{m}}-\mathrm{F}_{\mathrm{m}}{ }^{\prime}\right) / \mathrm{F}_{\mathrm{m}}{ }^{\prime}$ (Bilger and Bjorkman, 1990).

In addition to the $\mathrm{F}_{\mathrm{v}} / \mathrm{F}_{\mathrm{m}}$ and NPQ, the excitation energy partitioning was assessed. The quantum yield of photochemical energy conversion in PSII was calculated as $\phi_{\mathrm{II}}=\left(\mathrm{F}_{\mathrm{m}}{ }^{\prime}-\mathrm{F}_{\mathrm{s}}\right) / \mathrm{F}_{\mathrm{m}}{ }^{\prime}$ (Genty et al., 1989). The quantum yield of non-regulated energy that was dissipated in PSII $\left(\phi_{\mathrm{NO}}\right)$ and the quantum yield of regulated energy dissipation in PSII $\left(\phi_{\mathrm{NPO}}\right)$ was calculated according to Hendrickson et al., (2004) as follows: $\phi_{\mathrm{NO}}=\mathrm{F}_{\mathrm{s}} / \mathrm{F}_{\mathrm{m}}$ and $\phi_{\mathrm{NPQ}}=\left(\mathrm{F}_{\mathrm{s}} /\right.$ $\left.\mathrm{F}_{\mathrm{m}}{ }^{\prime}\right)-\left(\mathrm{F}_{\mathrm{s}} / \mathrm{F}_{\mathrm{m}}\right)$.

\section{Assay of lipid peroxidation}

The extent of lipid peroxidation in rice leaves was measured by the concentration of thiobarbituric acid-reacting substances (TBARS), as final products of lipid peroxidation. We used the Du and Bramlage (1992) method, which accounts for interferences conferred by carbohydrates. Fresh leaf material (160 mg) was homogenized in $2 \mathrm{~mL}$ of $0.1 \%(\mathrm{w} / \mathrm{v})$ trichloroacetic acid (TCA). The homogenate was centrifuged at $10,000 \times \mathrm{g}$ for $15 \mathrm{~min}$, and $1.5 \mathrm{~mL}$ of $0.65 \%(\mathrm{w} / \mathrm{v})$ TBA solution was added to $500 \mu \mathrm{L}$ of the supernatant and incubated in a water bath at $95{ }^{\circ} \mathrm{C}$ for $25 \mathrm{~min}$. The reaction was stopped by placing the samples in test tubes in an ice bath. These samples were centrifuged at 3,000 $\times \mathrm{g}$ for $10 \mathrm{~min}$, and 
the absorption of the supernatant was read at 440,532 and $600 \mathrm{~nm}$. The amount of TBARS was calculated from an extinction coefficient of $155 \mathrm{mM}^{-1} \mathrm{~cm}^{-1}$.

\section{Statistical analyses}

The experiment followed a randomized block factorial $(3 \times 2)$ design with three cultivars and two Fe-EDTA concentrations (except for chlorophyll $a$ fluorescence imaging, which was used for only one cultivar), with four replicates per treatment. The data were grouped into subdivided parcels, with each parcel representing the time of sampling $(1,3,5,7$ and 9 days). All data were subjected to an analysis of variance (two-way ANOVA) and the means were compared by Tukey's test at $5 \%$ probability with SAEG 9.1-UFV software (Fundação Arthur Bernardes, UFV, Viçosa, 2007). Prior to the ANOVA, all data sets were checked for their homogeneity of variance (Cochran's Q and Bartlett's tests) and normality (Lilliefors test).

\section{Results}

After three days of exposure to excess $\mathrm{Fe}$, all the cultivars showed increases $(p<0.001)$ in shoot iron concentration (Figure 1). After five days of exposure to excess $\mathrm{Fe}$, the differences between cultivars became visible. The BR IRGA 409 cultivar showed subsequent increases in iron uptake, reaching values above $600 \mathrm{mg}$ $\mathrm{kg}^{-1}$ DW after just five days. At day seven, the BR IRGA 409 cultivar had accumulated almost $1000 \mathrm{mg}_{\mathrm{Fe}} \mathrm{kg}^{-1}$ and the EPAGRI 107 cultivar exhibited the lowest values, which were below the critical toxicity level $1500 \mathrm{mg}_{\mathrm{Fe}}$ $\mathrm{kg}_{\mathrm{DM}}^{-1}$ ) (Stein et al., 2014). At the end of the experiment, the differences in shoot $\mathrm{Fe}$ concentration among the most sensitive (BR IRGA 409) and the other cultivars became greater leading to an interaction between Fe treatments and cultivars $(p<0.001)$.

Despite the short exposure time, excess Fe affected all the morphological variables for all the cultivars $(p<$ 0.05). Excessive $\mathrm{Fe}$ in the root medium caused a reduction in total shoot and root dry weights and the shoot and root lengths, regardless of exposure time (Table 1). These changes in shoot, root and total dry weights were consistent for all cultivars. However, the reduction in shoot and root lengths caused by excess Fe occurred differently between cultivars because these variables were not affected in the EPAGRI 107 cultivar. Independently of Fe treatments, the EPAGRI 107 cultivar had the lowest shoot dry weights and the lowest shoot and root lengths $(p<0.01)$.

In general, $\mathrm{Fe}$ excess affects the net photosynthetic rate $(A)$ in all rice cultivars. In the BR IRGA 409 cultivar the excess Fe treatment caused a lowered $A$ just after three days of exposure (Figure 2). The EPAGRI 107 cultivar only showed reductions in the A $(p<0.05)$ up to seven days of Fe-excess exposure" as found in the accepted version (to avoid misinterpretation). The BRSMG SELETA and BR IRGA 409 cultivars were the most sensitive and showed the lowest $A$ values up to five days of exposure, while the EPAGRI 107 cultivar kept constant $A$ even in higher doses of Fe-EDTA (Figure 2). Those changes in $A$ were not accompanied by lower values in the stomatal conductance $\left(g_{s}\right)$ and transpiration rate $(E)$, which did not change because of excess $\mathrm{Fe}$, though they showed differences only between cultivars. By contrast, an increased $C_{\mathrm{i}} / C_{\mathrm{a}}$ ratio was observed in all cultivars after the excess Fe treatment, which was similar to the changes in net photosynthesis (Figure 2).

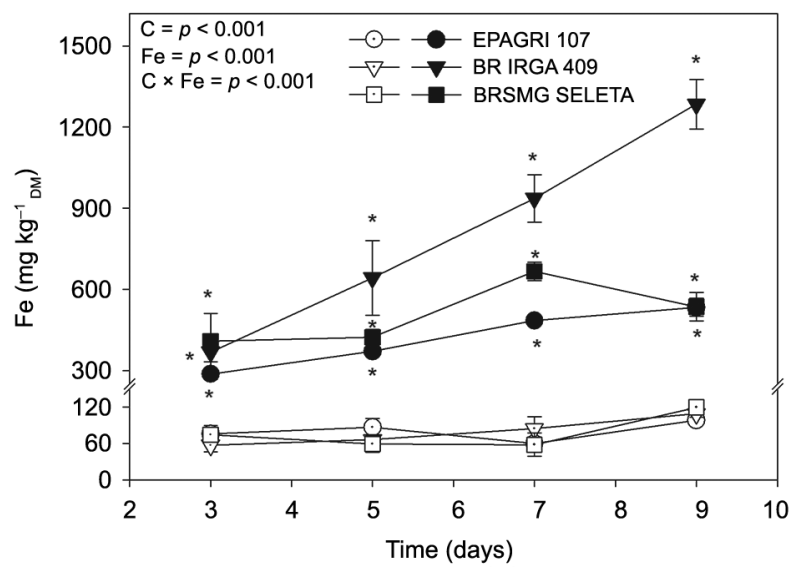

Figure 1 - The iron concentration of the shoots from three rice cultivars over the time of exposure to $7 \mathrm{mM}$ Fe-EDTA (closed symbols) or control (open symbols) treatments in a nutrient solution. The data are presented as the means \pm standard errors of four replicates. Significant differences between cultivars (C), FeEDTA treatments $(\mathrm{Fe})$ and their interaction $(\mathrm{C} \times \mathrm{Fe})$ are given in the panels. Asterisks indicate significant differences $(p<0.05)$ between Fe-EDTA treatments in a given time.

Table 1 - Plant total dry weight (TDW), dry weights of the shoot (SDW) and root (RDW), and the lengths of the shoot (SL) and root (RL) of three rice cultivars exposed to $7 \mathrm{mM}$ Fe-EDTA or the control (0.009 $\mathrm{mM}$ Fe-EDTA) in a nutrient solution.

\begin{tabular}{lcccccc}
\hline Cultivar & Treatment & TDW $(\mathrm{g})$ & SDW $(\mathrm{g})$ & RDW $(\mathrm{g})$ & $\mathrm{SL}(\mathrm{cm})$ & $\mathrm{RL}(\mathrm{cm})$ \\
\hline \multirow{2}{*}{ EPAGRI 107 } & Control & $20.64 \pm 0.7^{\mathrm{Ba}}$ & $17.15 \pm 0.6^{\mathrm{Ba}}$ & $3.50 \pm 0.1^{\mathrm{Aa}}$ & $26.36 \pm 0.6^{\mathrm{Ba}}$ & $34.34 \pm 0.9^{\mathrm{Ba}}$ \\
& Fe-EDTA & $16.71 \pm 0.8^{\mathrm{Bb}}$ & $13.68 \pm 0.7^{\mathrm{Bb}}$ & $3.03 \pm 0.1^{\mathrm{Ab}}$ & $24.66 \pm 0.4^{\mathrm{Ba}}$ & $36.07 \pm 1.0^{\mathrm{Aa}}$ \\
\hline \multirow{2}{*}{ IRGA 409 } & Control & $23.14 \pm 1.0^{\mathrm{Aa}}$ & $19.52 \pm 0.9^{\mathrm{Aa}}$ & $3.62 \pm 0.3^{\mathrm{Aa}}$ & $39.69 \pm 1.3^{\mathrm{Aa}}$ & $44.34 \pm 1.4^{\mathrm{Aa}}$ \\
& Fe-EDTA & $19.69 \pm 0.9^{\mathrm{Ab}}$ & $16.52 \pm 0.8^{\mathrm{Ab}}$ & $3.16 \pm 0.2^{\mathrm{Ab}}$ & $33.48 \pm 1.0^{\mathrm{Ab}}$ & $39.73 \pm 0.9^{\mathrm{Ab}}$ \\
\hline \multirow{2}{*}{ BRSMG SELETA } & Control & $23.19 \pm 1.3^{\mathrm{Aa}}$ & $19.54 \pm 1.1^{\mathrm{Aa}}$ & $3.65 \pm 0.2^{\mathrm{Aa}}$ & $27.58 \pm 0.3^{\mathrm{Ba}}$ & $35.81 \pm 1.0^{\mathrm{Ba}}$ \\
& Fe-EDTA & $21.52 \pm 1.1^{\mathrm{Ab}}$ & $18.11 \pm 1.0^{\mathrm{Ab}}$ & $3.41 \pm 0.2^{\mathrm{Ab}}$ & $25.53 \pm 0.4^{\mathrm{Bb}}$ & $31.89 \pm 0.7^{\mathrm{Bb}}$ \\
\hline
\end{tabular}

The data are the means and standard errors. Capital letters compare cultivars and small letters compare iron treatments. The data are presented as the means of all days of exposure to the treatments due to non-significant interaction between time and $\mathrm{Fe}$. 
The chlorophyll index of cultivars EPAGRI 107 and BRSMG SELETA did not change $(p>0.05)$ under excess Fe (Figure 3). On the other hand, after seven days of excess Fe exposure, there was a reduction in total chlorophyll, and chlorophyll $a$ and $b$ levels in the BR IRGA 409 cultivar (Figure 3).

An increased TBARS concentration was observed in all cultivars, even after three days of excess Fe exposure. The BR IRGA 409 cultivar exhibited a higher TBARS level compared to other two cultivars (Figure 4), leading to an interaction between Fe treatments and cultivars $(p<0.001)$. This finding was consistent with the changes found for chlorophyll a fluorescence in the BR IRGA 409 cultivar (Figure 5 and 6). At the end of the exposure time, a reduction was observed $(p<0.05)$ in the $\mathrm{F}_{\mathrm{v}} / \mathrm{F}_{\mathrm{m}}$ and an increase in the $\mathrm{F}_{0}$ values (Figure 5). The iron toxicity effects were more severe at the leaf extremities, as assessed by $\mathrm{F}_{\mathrm{v}} / \mathrm{F}_{\mathrm{m}}$ imaging (Figure 5).

The fate of the absorbed light energy was evaluated by using a light curve for chlorophyll $a$ fluorescence throughout the time of exposure of the BR IRGA 409 cultivar to excess Fe (Figure 6). Fe excess leads to rises in $\phi_{\mathrm{NO}}(p<0.01)$ and decreases in $\phi_{\mathrm{NPQ}}(p<0.05)$ values. This response was consistent over the course

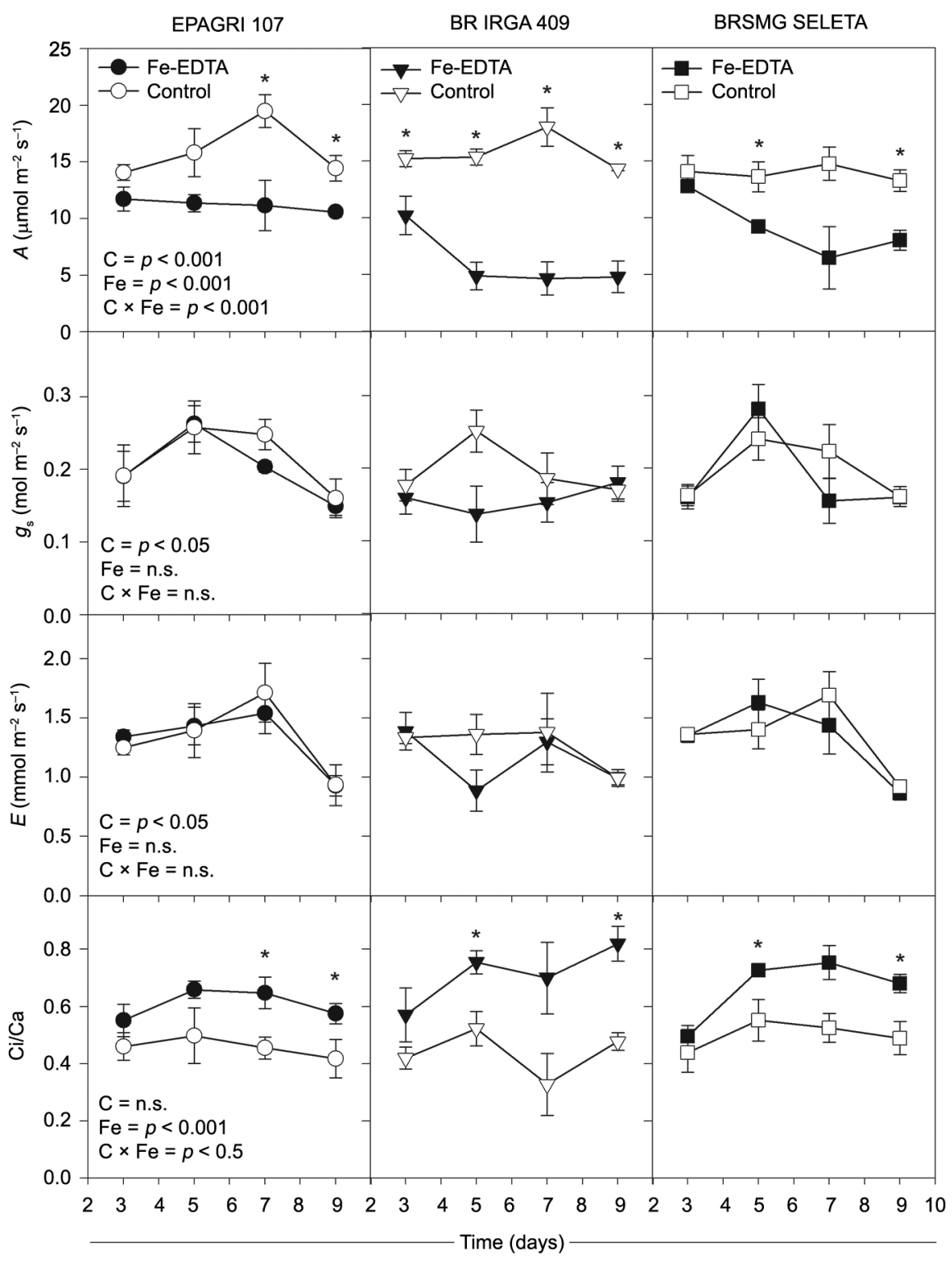

Figure 2 - The net photosynthetic rate $(A)$, stomatal conductance $\left(g_{s}\right)$, transpiration $(E)$ and $\mathrm{Ci} / \mathrm{Ca}$ ratio of three rice cultivars over the time of exposure to $7 \mathrm{mM}$ Fe-EDTA (closed symbols) or control (open symbols) treatments in a nutrient solution. The data are presented as the means \pm standard errors of four replicates. Significant differences between cultivars (C), Fe-EDTA treatments (Fe) and their interaction (C $\times$ Fe) are given in the panels. Asterisks indicate significant differences $(p<0.05)$ between Fe-EDTA treatments in a given time. n.s.: not significant. 
of the evaluations and became evident with interaction $(p<0.05)$ between Fe treatments and high irradiances at the seventh day (Figure 6). The $\phi_{\text {II }}$ changed only from the seventh day on of evaluation $(p<0.01)$, when it was decreased by excess iron treatment. The Fe excess also reduced NPQ values even after the first day of plant exposure $(p<0.05)$. Interaction between Fe treatments and photosynthetic photon flux density $(p<0.01)$ was observed at the seventh day, primarily under irradiances above $500 \mu \mathrm{mol}$ photons $\mathrm{m}^{-2} \mathrm{~s}^{-1}$ (Figure 7).

\section{Discussion}

The oxidative damage induced by excess iron was evident after only three days of Fe-EDTA $(7 \mathrm{mM})$ treatment in all the rice cultivars, as assessed by the TBARS values. Membrane lipids are especially prone to attack by free radicals and, although it is not being the primary cytotoxic target, it is considered a reliable indicator of oxidative stress in plants (Halliwell, 1987). A wide range of different extreme environmental conditions can induce excessive ROS generation, with emphasis on exposures to

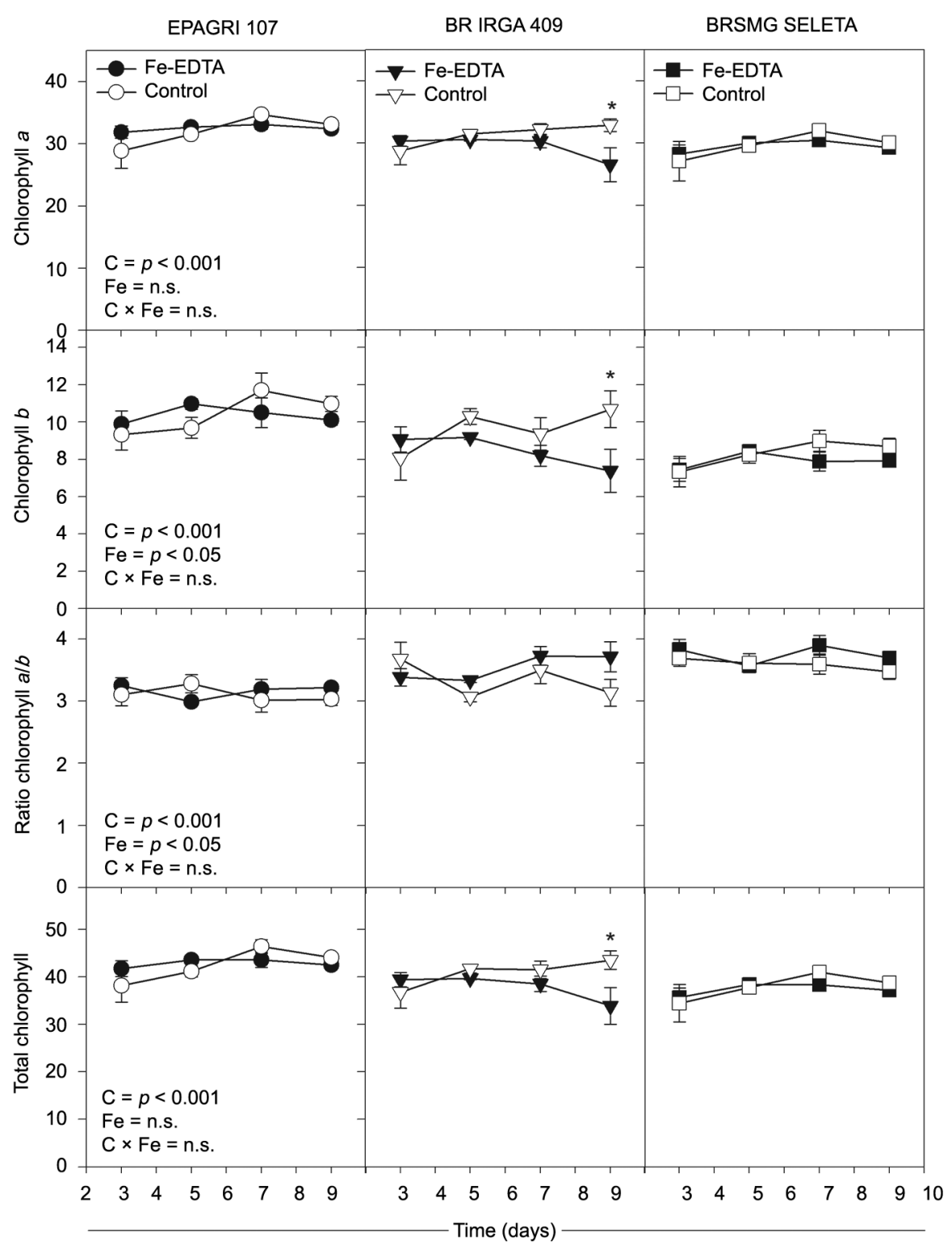

Figure 3 - The index of chlorophyll $a$, chlorophyll $b$, ratio chlorophyll $a / b$ and total chlorophyll of three rice cultivars over the time of exposure to $7 \mathrm{mM} \mathrm{Fe}$-EDTA (closed symbols) or control (open symbols) treatments in a nutrient solution. The data are presented as the means \pm standard errors of four replicates. Significant differences between cultivars (C), Fe-EDTA treatments ( $\mathrm{Fe}$ ) and their interaction $(\mathrm{C} \times \mathrm{Fe})$ are given in the panels. Asterisks indicate significant differences $(p<0.05)$ between Fe-EDTA treatments in a given time. n.s.: not significant. 


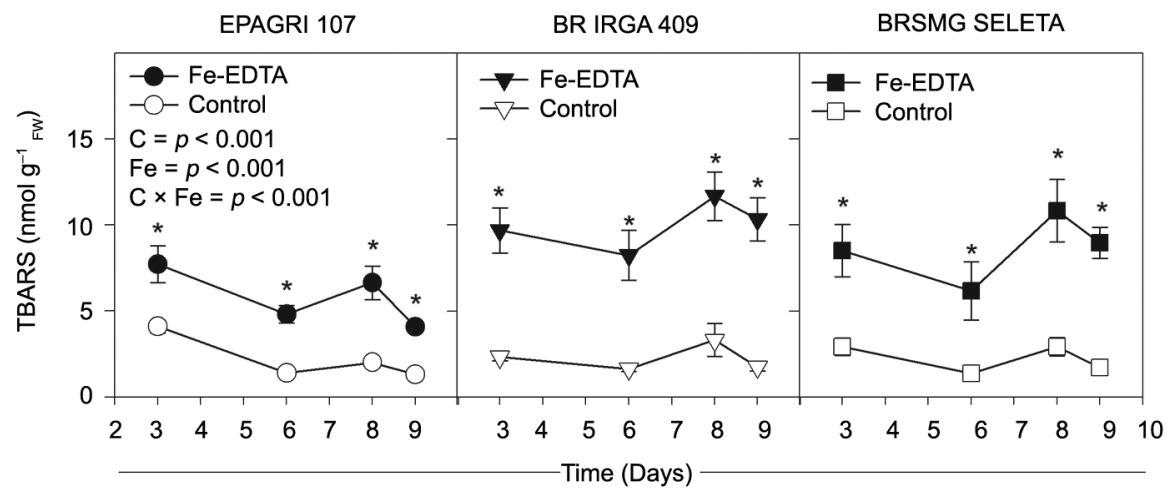

Figure 4 - The thiobarbituric acid-reacting substances (TBARS) concentration of three rice cultivars over the time of exposure to 7 mM Fe-EDTA (closed symbols) or control (open symbols) treatments in a nutrient solution. The data are presented as the means \pm standard errors of four replicates. Significant differences between cultivars $(\mathrm{C})$, Fe-EDTA treatments $(\mathrm{Fe})$ and their interaction $(\mathrm{C} \times \mathrm{Fe})$ are given in the panels. Asterisks indicate significant differences $(p<0.05)$ between Fe-EDTA treatments in a given time. n.s.: not significant.
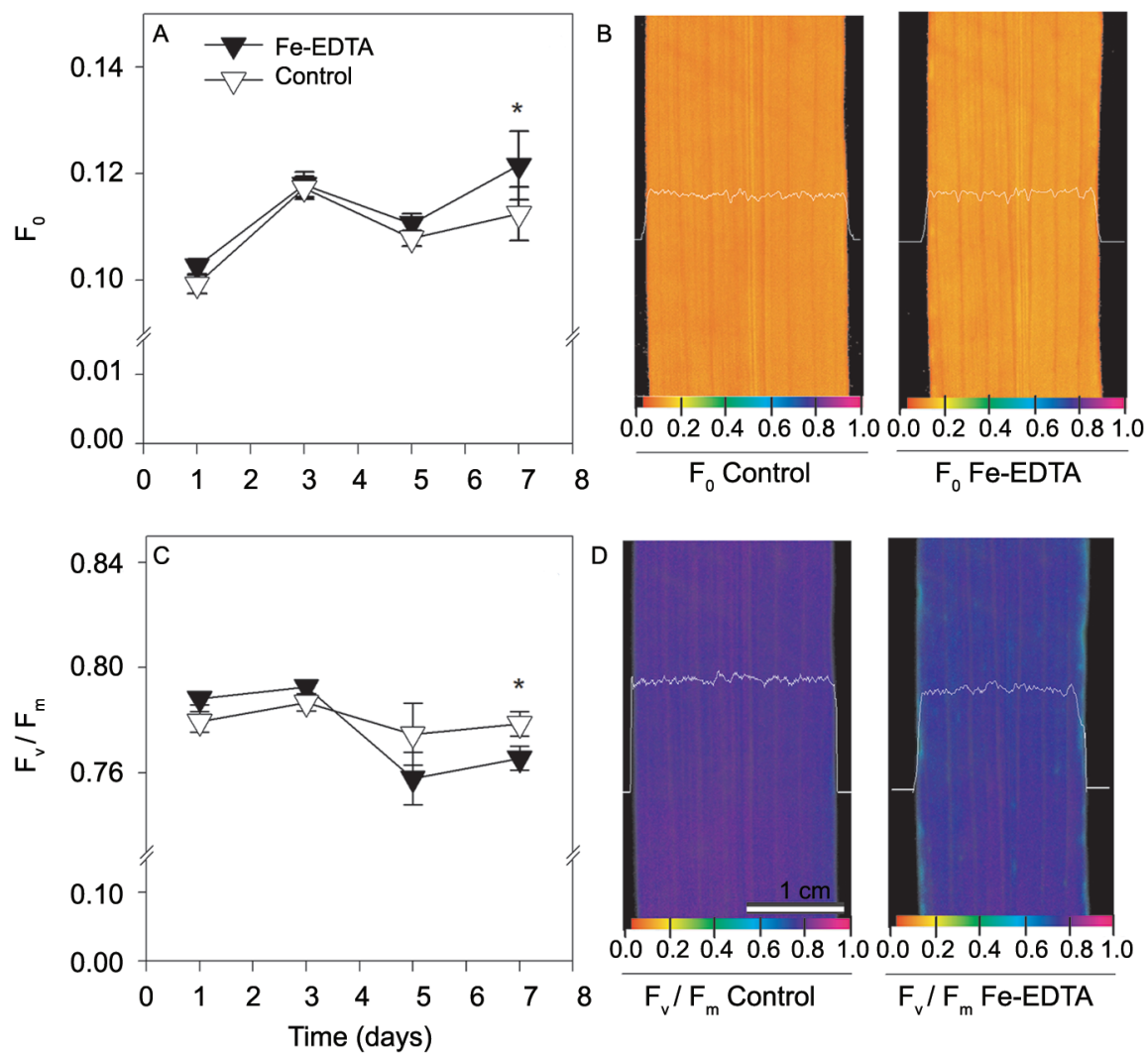

Figure 5 - Changes in minimal fluorescence $\left(F_{0} ; A\right)$ and spatial variation in $F_{0}(B)$, maximal $P S I l$ quantum yield $\left(F_{\sqrt{ }} / F_{m} ; C\right)$ and spatial variation in $F_{\downarrow} /$ $F_{m}(D)$ of the sensitive rice cultivar BR IRGA 409 under control conditions with control (open symbols) or with 7 mM Fe-EDTA (closed symbols) in a nutrient solution. Spatial variation is presented across a transection of the leaf blade at the seventh day of treatment. The imaging data were taken from a representative replicate. The false color code depicted at the bottom of the images ranges from 0.000 (black) to 1.000 (pink). The data for $A$ and $C$ are presented as the means \pm standard errors of four replicates. Asterisks indicate significant differences $(p<$ 0.05) between Fe-EDTA treatments in a given time.

high concentrations of transition metals such as $\mathrm{Fe}$, that promote the most reactive compounds such as singlet oxygen $\left({ }^{1} \mathrm{O}_{2}\right)$, superoxide anion radicals $\left(\mathrm{O}_{2}{ }^{*}-1\right.$, hydrogen peroxide $\left(\mathrm{H}_{2} \mathrm{O}_{2}\right)$ and hydroxyl radicals $\left(\mathrm{HO}^{*}\right)$. Hydroxyl radicals are the major damaging species produced under iron excess by the Fenton reaction (Halliwell, 1987).

For the most sensitive cultivar, BR IRGA 409, the oxidative damage might have been inflicted earlier since 


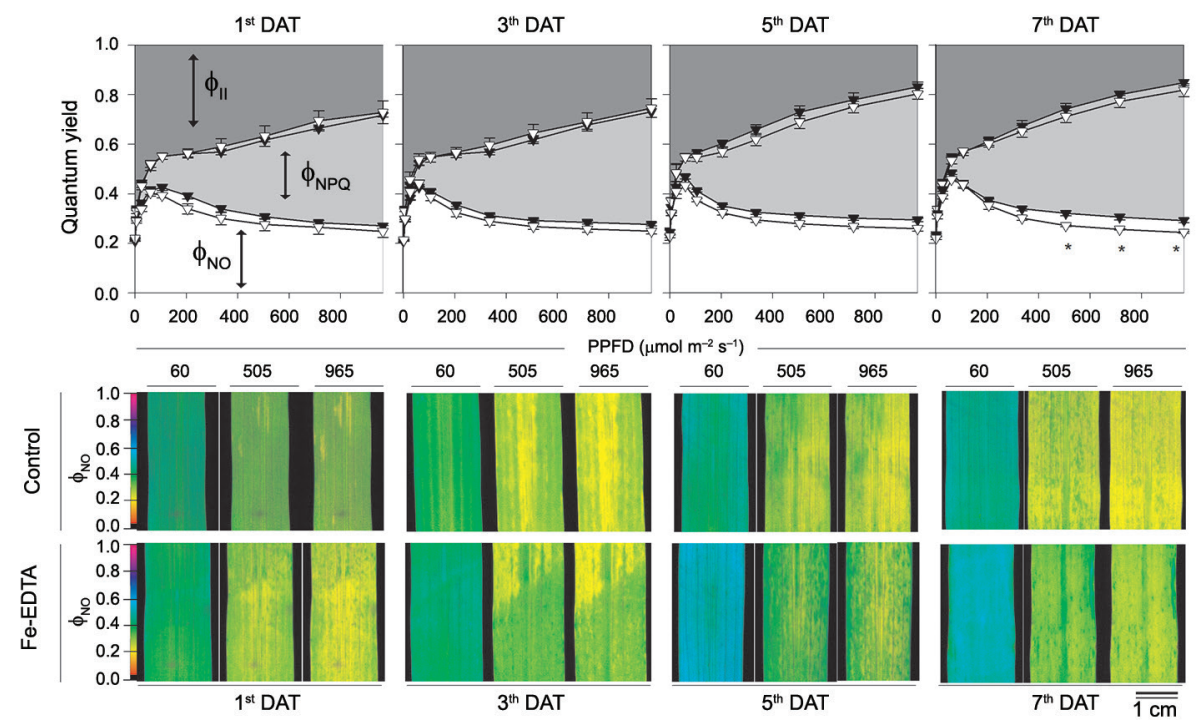

Figure 6 - The light response curve of the quantum yield for photochemical energy conversion in PSII ( $\phi_{\text {III }}$, and the quantum yield of regulated $\left(\phi_{\mathrm{NPQ}}\right)$ and non-regulated $\left(\phi_{\mathrm{NO}}\right)$ energy dissipation in PSII of the sensitive rice cultivar BR IRGA 409 under control conditions (open symbols) or under $7 \mathrm{mM}$ Fe-EDTA (closed symbols) in a nutrient solution. The fluorescence images of $\phi_{\mathrm{No}}$ at different photosynthetic photon flux density (PPFD) values are also presented. The imaging data were taken from a representative replicate. The false color code depicted ranges from 0.000 (black) to 1.000 (pink). The data are presented as the means \pm standard errors of four replicates. Asterisks indicate significant differences $(p<0.05)$ between Fe-EDTA treatments in a given time.
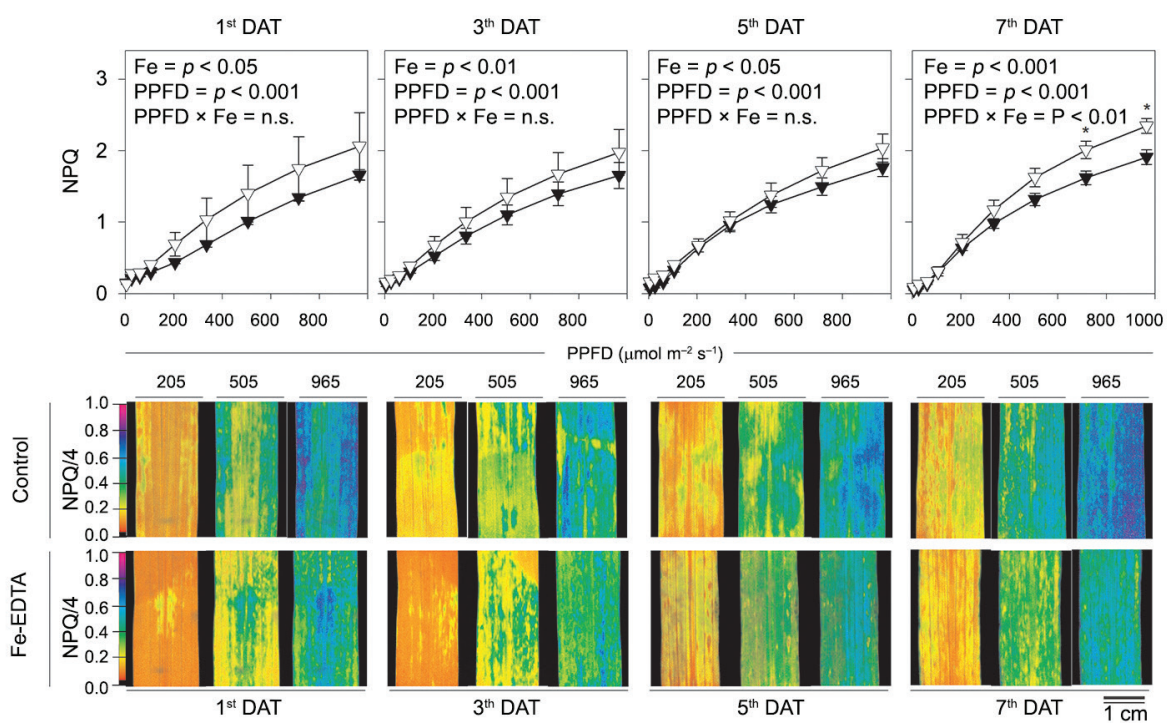

Figure 7 - The light response curve of non-photochemical quenching (NPQ) in the sensitive BR IRGA 409 rice cultivar under control conditions (open symbols) and under $7 \mathrm{mM}$ Fe-EDTA (closed symbols) in a nutrient solution. Fluorescence images of NPQ are also presented as different photosynthetic photon flux density (PPFD) values. The imaging data were taken from a representative replicate. The false color code depicts ranges from 0.000 (black) to 1.000 (pink). The data are presented as the means \pm standard errors of four replicates. Significant differences between Fe-EDTA treatments (Fe), PPFD and their interaction (Fe $\times$ PPFD) are given in the panels. Asterisks indicate significant differences ( $p$ $<0.05$ ) between Fe-EDTA treatments in a given time. n.s.: not significant.

important changes in the chlorophyll a fluorescence were detected after only one day of excess Fe exposure (see below). This finding is consistent with the high shoot iron concentration observed in this cultivar (BR IRGA 409), and the most tolerant cultivar (EPAGRI 107) maintaining its shoot iron concentration below the critical toxicity level (500 $\mathrm{mg}_{\mathrm{Fe}} \mathrm{kg}^{-1}{ }_{\mathrm{DM}}$ ) (Stein et al., 2014). In fact, the iron uptake rate of the BR IRGA 409 cultivar continued to increase throughout the experimental period, reaching values of $143 \mathrm{mg}_{\mathrm{Fe}} \mathrm{kg}_{\mathrm{DW}}^{-1} \mathrm{~d}^{-1}$, and the other 
cultivars (EPAGRI 107 and BRSMG SELETA) reduced their uptake rates to below $60 \mathrm{mg}_{\mathrm{Fe}} \mathrm{kg}^{-1} \mathrm{DW}^{-1}$.

Using mechanisms to maintain iron homeostasis, plants tightly control Fe uptake, utilization, and storage in response to environmental availability (Kobayashi and Nishizawa, 2012). The results reported here indicate that the resistance to excess iron toxicity that was exhibited by the EPAGRI 107 cultivar may involve a mechanism of avoidance, which prevents high levels of iron in shoots. It may be achieved by the regulation of Fe uptake, as seen by Silveira et al., (2009). In fact, the oxidation of $\mathrm{Fe}^{2+}$ to $\mathrm{Fe}^{3+}$ at the root surface, resulting in a typical orange precipitate known as iron plaque, was reported previously for the EPAGRI 107 cultivar (Pereira et al., 2014). However, even resistant cultivars, closely related to the EPAGRI 107 cultivar, may present different tolerance strategies to cope with iron overload (Stein et al., 2014). As recently reported, while the EPAGRI 108 cultivar accumulates higher levels of iron in its roots thus lowering translocation to shoots, its counterpart, EPAGRI 109 showed higher iron concentration in leaf tissues coupled with an effective antioxidant response (Stein et al., 2014).

The strategies to prevent excessive Fe accumulation in the shoots may not attest resistance to oxidative damage, once the BRSMG SELETA cultivar had shown higher sensitivity even with a concentration of Fe similar to EPAGRI 107. Tissue Fe concentrations did not completely indicate the plants' physiological resistance status (Müller et al., 2015). Visual symptoms in rice may appear with leaf $\mathrm{Fe}$ concentration as low as $108 \mathrm{mg}_{\mathrm{Fe}}$ $\mathrm{kg}^{-1}{ }_{\mathrm{DM}}$ to $250 \mathrm{mg}_{\mathrm{Fe}} \mathrm{kg}^{-1}{ }_{\mathrm{DM}}$ (Genon et al., 1994; Ramírez et al., 2002). Oryza glaberrima, however, accumulates more than $2200 \mathrm{mg}_{\mathrm{Fe}} \mathrm{kg}^{-1}$ DM in leaves without exhibiting any Fe-toxicity symptoms (Majerus et al., 2007). Also cultivars with different sensitivity to iron excess can show similar shoot Fe content, above the toxicity level (Sahrawat et al., 1996).

The action of the antioxidant-system defense also takes place under excess $\mathrm{Fe}$ exposure to maintain $\mathrm{Fe}$ homeostasis at the cellular level. Low molecular mass antioxidants (ascorbic acid, glutathione) and ROS-interacting enzymes such as superoxide dismutase (SOD), glutathione reductase (GR), ascorbate peroxidase (APX) dehydroascorbate reductase (DHAR) may act as tissue tolerance mechanisms to eliminate or reduce the damaging effects caused by Fe overload (Stein et al., 2014; Wu et al., 1998). In excess Fe-resistant plants, the antioxidant system may be sufficient to prevent biological damage as mediated by ROS, which keeps the deleterious effects to a minimum (Müller et al., 2015; Stein et al., 2014).

Among all the evaluated gas exchange variables, the first changes in response to excess Fe were observed in the net photosynthetic rate, prior to stomatal closure as reported in other works (Dufey et al., 2009; Pereira et al., 2013). The earlier reduction in net photosynthesis, as observed at three days of excess Fe exposure in the sensitive BR IRGA 409 cultivar, is attributed to nonstomatal limitations that increased $C \mathrm{i} / \mathrm{C}$ a values and was triggered by energy partitioning impairment and oxidative damage, that precede stomatal closure and loss of chlorophyll. Besides the impairment of photosynthetic efficiency, the oxidative damage due to Fe-excess may result in increased photorespiration and expression of related genes (Müller et al., 2015; Pereira et al., 2013).

The cell membrane is the primary site of attack by metal-generated ROS, and the chloroplast is especially prone to oxidative stress because of light-driven photosynthetic processes under high $\mathrm{O}_{2}$ concentrations (Halliwell, 1987; Wu et al., 1998). Thus, iron excess in leaf tissues may contribute to increased damage triggered by ROS once the superoxide anion radical $\left(\mathrm{O}_{2}{ }^{*}-1\right.$, which can be generated by the photosynthetic electron transport chain, also participates in the formation of the highlyreactive hydroxyl radical $\left(\mathrm{HO}^{*}\right)$ through the Fenton reaction and the Haber-Weiss cycle, which require free $\mathrm{Fe}^{2+}$ (Halliwell, 1987; Wu et al., 1998).

The oxidative damage observed after only three days of iron overload did not affect the photosynthetic pigments at this time or during the whole experimental period in the less sensitive cultivars. Although chlorophyll molecules may be degraded by ROS (Neves et al., 2009), these pigments were not the first target of ironinduced oxidative stress. On the other hand, iron is required for chlorophyll biosynthesis (Msilini et al., 2011), and the chlorophyll index may increase in plants that are exposed to an iron overload (Pereira et al., 2013). The reduced pigment index after seven days of $\mathrm{Fe}$ overload for the sensitive BR IRGA 409 cultivar is related to degradation that is mediated by oxidative stress /Gallego et al., 1996) and not by a limitation in the chlorophyll synthesis. The changes in the $\mathrm{F}_{0}$ and $\mathrm{F}_{\mathrm{v}} / \mathrm{F}_{\mathrm{m}}$ values for the BR IRGA 409 cultivar occurred only after a reduction in chlorophyll at the end of the experimental period. These changes indicate impairment in the energy transfer from antenna pigments to the reaction center and an increased susceptibility to photoinhibition with reduced PSII effectiveness in the primary photochemical reactions. However, the changes in other chlorophyll fluorescence variables become evident earlier than the chlorophyll degradation and may be attributed primarily to oxidative damage. Thylakoid membranes are enriched in polyunsaturated fatty acids that are particularly susceptible to ROS. The loss of connectivity among active PSII units from excess iron have been previously reported (Pereira et al., 2013), and the membrane lipid disruption as assessed by TBARS values leads to important effects on chlorophyll fluorescence variables. Among them, the increase in $\phi_{\mathrm{NO}}$ value $(p<0.05)$ just after the first day of Fe-excess exposure indicates the plant's inability to dissipate excess energy by photochemistry or protective regulatory mechanisms. Once related to nonregulated and constitutive non-radiative decay processes (Kramer et al., 2004), the rise in $\phi_{\mathrm{NO}}$ is also indicative of the extended lifetimes of chlorophyll excitation and may thus contribute to the generation of triplet state chlorophylls and more reactive oxygen species and radicals, 
maximizing the oxidative damage in excess iron-exposed plants, mainly at higher irradiances. The damage to photochemical components became severe after seven days of exposure to iron excess leading to further impairment in energy conversion to photochemistry $\left(\mathrm{F}_{\mathrm{v}} / \mathrm{F}_{\mathrm{m}}\right.$ and $\left.\phi_{\mathrm{II}}\right)$ and in regulated non-photochemical dissipation $\left(\phi_{\mathrm{NPO}}\right)$.

The inability to quench energy safely by protective regulatory mechanisms or by photochemistry was also demonstrated by the reduced NPQ values after one day of Fe-excess exposure. NPQ is an important mechanism in plants that protects PSII reaction centers from damage through the dissipation of excess light energy as heat. The major component of NPQ is the energy or $\mathrm{pH}$ dependent component $\left(q_{\mathrm{E}}\right)$. This component is triggered by a decrease in $\mathrm{pH}$ within the thylakoid lumen, inducing the interconversion of specific xanthophyll pigments (Müller et al., 2015; Müller et al., 2001). The oxidative damage, as indicated by the TBARS concentration in the sensitive cultivar, may disrupt the membrane integrity of the thylakoid and hinders the formation of a transmembrane electrochemical potential gradient in the chloroplasts through lipid peroxidation, preventing NPQ buildup. The susceptibility of NPQ to high Fe concentrations in leaves has been reported previously (Neves et al., 2009; Pereira et al., 2013).

The use of resistant rice cultivars and adequate water and nutrient management constitute the most costeffective way to control yield losses caused by iron toxicity (Becker and Asch, 2005; Silveira et al., 2009). However, the improved development of resistant varieties will require knowledge about its photosynthetic responses under Fe excess conditions, and it will unravel the toxic effects on photosynthesis in the sensitive ones. Photosynthetic parameters can be useful for the future selection of rice genotypes and varieties with higher productivity in environments in which biomass production is the major limiting factor for yield (Hubbart et al., 2007).

In conclusion, the different responses to excess iron in tolerant and sensitive rice cultivars are related to oxidative damage buildup and plasticity in light energy utilization. The higher sensitivity to excess iron in some rice cultivars is caused by the severe impairment of photosynthesis by non-stomatal limitation as triggered by oxidative damage and its consequent inability to quench excess energy by regulated dissipation. The effects of excess iron on chlorophyll a fluorescence variables (such as $\phi_{\mathrm{NO}}$ and NPQ) were detected after one day of Fe treatment, much earlier than the onset of visual symptoms. Therefore, it is suggested that these non-photochemical chlorophyll a fluorescence parameters can be used worldwide for future studies on rice variety selection in lowland environments exposed to Fe toxicity.

\section{Acknowledgments}

We thank the Brazilian Enterprise of Agropecuary Research (EMBRAPA) and the Agricultural Research Company of Minas Gerais (EPAMIG) for providing us with rice seeds. We also thank the Plant Biology Department at the Federal University of Viçosa for the use of their Imaging-PAM fluorometer and an anonymous reviewer for constructive comments on the manuscript. This work was supported by the Minas Gerais State Foundation for Research Support (FAPEMIG) [grant number CRA-APQ-02275-10 and ETC-00004-13 to E.G.P], Brazil. A.E.S. and S.S.P. are grateful to the Brazilian National Council for Scientific and Technological Development (CNPq) and FAPEMIG for scholarships.

\section{References}

Becker, M.; Asch, F. 2005. Iron toxicity in rice-condition and management concepts. Journal of Plant Nutrition and Soil Science 168: 558-573.

Bilger, W.; Bjorkman, O. 1990. Role of the xanthophyll cycle in photoprotection elucidated by measurements of light-induced absorbency changes, fluorescence and photosynthesis in leaves of hedera-canariensis. Photosynthesis Research 25: 173-185.

Counce, P.A.; Keisling, T.C.; Mitchell, A.J. 2000. A uniform, objective and adaptive system for expressing rice development. Crop Science 40: 436-443.

Dobermann, A.; Fairhurst, T. 2000. Rice: Nutrient Disorders \& Nutrient Management. International Rice Research Institute, Los Baños, Philippines.

Dorlodot, S.; Lutts, S.; Bertin, P. 2005. Effects of ferrous iron toxicity on the growth and mineral composition of an interspecific rice. Journal of Plant Nutrition 28: 1-20.

Du, Z.; Bramlage, W.J. 1992. Modified thiobarbituric acid assay for measuring lipid oxidation in sugar-rich plant tissue extracts. Journal of Agricultural and Food Chemistry 40: 1566-1570.

Dufey, I.; Hakizimana, P.; Draye, X.; Lutts, S.; Bertin, P. 2009. QTL mapping for biomass and physiological parameters linked to resistance mechanisms to ferrous iron toxicity in rice. Euphytica 167: 143-160.

Gallego, S.M.; Benavides, M.P.; Tomaro, M.L. 1996. Effect of heavy metal ion excess on sunflower leaves: evidence for involvement of oxidative stress. Plant Science 121: 151-159.

Genon, J.; Hepcée, N.; Duffey, J.; Delvaux, B.; Hennebert, P. 1994. Iron toxicity and other chemical soil constraints to rice in highland swamps of Burundi. Plant and Soil 166: 109-115.

Genty, B.; Briantais, J.M.; Baker, N.R. 1989. The relationship between the quantum yield of photosynthetic electron transport and quenching of chlorophyll fluorescence. Biochimica et Biophysica Acta 990: 87-92.

Guerinot, M.L.; Yi, Y. 1994. Iron: nutritious, noxious, and not readily available. Plant Physiology 104: 815-820.

Halliwell, B. 1987. Oxidative damage, lipid peroxidation and antioxidant protection in chloroplasts. Chemistry and Physics of Lipids 44: 327-340.

Hendrickson, L.; Furbank, R.T.; Chow, W.S. 2004. A simple alternative approach to assessing the fate of absorbed light energy using chlorophyll fluorescence. Photosynthesis Research 82: 73-81.

Hoagland, D.R.; Arnon, D.I. 1938. The Method for Growing Plants without Soil: Water-Culture. University of California, Berkeley, CA, USA. 
Hubbart, S.; Peng, S.; Horton, P.; Chen, Y.; Murchie, E.H. 2007. Trends in leaf photosynthesis in historical rice varieties developed in the Philippines since 1966. Journal of Experimental Botany 58: 3429-3438.

Kitajima, M.; Butler, W.L. 1975. Quenching of chlorophyll fluorescence and primary photochemistry in chloroplasts by dibromothymoquinone. Biochimica et Biophysica Acta 376: 105-115.

Kobayashi, T.; Nishizawa, N.K. 2012. Iron uptake, translocation, and regulation in higher plants. Annual Review of Plant Biology 63: 131-152.

Kramer, D.M.; Johnson, G.; Kiirats, O.; Edwards, G.E. 2004. New fluorescence parameters for the determination of $\mathrm{QA}$ redox state and excitation energy fluxes. Photosynthesis Research 79: 209-218.

Majerus, V.; Bertin, P.; Lutts, S. 2007. Effects of iron toxicity on osmotic potential, osmolytes and polyamines concentrations in the African rice (Oryza glaberrima Steud.). Plant Science 173: 96-105.

Msilini, N.; Zaghdoudi, M.; Govindachary, S.; Lachaâl, M.; Ouerghi, Z.; Carpentier, R. 2011. Inhibition of photosynthetic oxygen evolution and electron transfer from the quinone acceptor QA - to QB by iron deficiency. Photosynthesis Research 107: 247-256.

Müller, C.; Kuki, K.; Pinheiro, D.; de Souza, L.; Siqueira-Silva, A.; Loureiro, M.; Oliva, M.; Almeida, A. 2015. Differential physiological responses in rice upon exposure to excess distinct iron forms. Plant and Soil 391: 123-138.

Müller, P.; Li, X.P.; Niyogi, K.K. 2001. Non-photochemical quenching: a response to excess light energy. Plant Physiology 125: 1558-1566.

Neves, N.R.; Oliva, M.A.; Centeno, D.C.; Costa, A.C.; Ribas, R.F.; Pereira, E.G. 2009. Photosynthesis and oxidative stress in the restinga plant species Eugenia uniflora L. exposed to simulated acid rain and iron ore dust deposition: potential use in environmental risk assessment. Science of The Total Environment 407: 3740-3745.

Oxborough, K.; Baker, N.R. 1997. Resolving chlorophyll a fluorescence images of photosynthetic efficiency into photochemical and non-photochemical components: calculation of $\mathrm{qP}$ and $\mathrm{Fv}^{\prime} / \mathrm{Fm}^{\prime}$ without measuring $\mathrm{FO}^{\prime}$. Photosynthesis Research 54: 135-142.
Pereira, E.G.; Oliva, M.A.; Rosado-Souza, L.; Mendes, G.C.; Colares, D.S.; Stopato, C.H.; Almeida, A.M. 2013. Iron excess affects rice photosynthesis through stomatal and non-stomatal limitations. Plant Science 201-202: 81-92.

Pereira, E.G.; Oliva, M.A.; Siqueira-Silva, A.I.; Rosado-Souza, L.; Pinheiro, D.T.; Almeida, A.M. 2014. Tropical rice cultivars from lowland and upland cropping systems differ in iron plaque formation. Journal of Plant Nutrition 37: 1373-1394.

Ramírez, L.M.; Claassen, N.; Unieira, A.A.; Werner, H.; Moawad, A.M. 2002. Effect of phosphorus, potassium and zinc fertilizers on iron toxicity in wetland rice (Oryza sativa L.). Plant and Soil 239: 197-206.

Sahrawat, K.L.; Mulbah, C.K.; Diatta, S.; Delaune, R.D.; Patrick, W.H.; Singh, B.N.; Jones, M.P. 1996. The role of tolerant genotypes and plant nutrients in the management of iron toxicity in lowland rice. Journal of Agricultural Science 126: 143-149.

Silveira, V.C.; Fadanelli, C.; Sperotto, R.A.; Stein, R.J.; Basso, L.A.; Santos, D.S.; Vaz Junior, I.d.S.; Dias, J.F.; Fett, J.P. 2009. Role of ferritin in the rice tolerance to iron overload. Scientia Agricola 66: 549-555.

Soares, P.C.; Cornélio, V.M.O.; Reis, M.d.S.; Soares, A.A.; Vieira, A.R.; Rangel, P.H.N.; Cutrim, V.d.A. 2005. BRSMG Seleta: a new rice cultivar for lowland areas in Minas Gerais. Revista Ceres 52: 509-516 (in Portuguese, with abstract in English).

Stein, R.J.; Lopes, S.I.G.; Fett, J.P. 2014. Iron toxicity in fieldcultivated rice: contrasting tolerance mechanisms in distinct cultivars. Theoretical and Experimental Plant Physiology 26: 135-146.

Tedesco, M.J.; Gianello, C.; Bissani, C.A.; Bohnen, H.; Volkweiss, S.J. 1997. Analysis of soil, plants and other materials = Análise de solo, plantas e outros materiais. 2ed. Editora UFRGS, Porto Alegre, RS, Brazil (in Portuguese).

Wu, P.; Hu, B.; Liao, C.Y.; Zhu, J.M.; Wu, Y.R.; Senadhira, D.; Paterson, A.H. 1998. Characterization of tissue tolerance to iron by molecular markers in different lines of rice. Plant and Soil 203: 217-226.

Yadavalli, V.; Neelam, S.; Rao, A.S.V.C.; Reddy, A.R.; Subramanyam, R. 2012. Differential degradation of photosystem I subunits under iron deficiency in rice. Journal of Plant Physiology 169: 753-759. 